Article

\title{
A Transformed Triangular Vegetation Index for Estimating Winter Wheat Leaf Area Index
}

\author{
Naichen Xing ${ }^{1,2}$, Wenjiang Huang ${ }^{1,3, *}$, Qiaoyun Xie ${ }^{4}$, Yue Shi ${ }^{5}{ }^{\circledR}$, Huichun $\mathrm{Ye}^{3}{ }^{\mathbb{D}}$, \\ Yingying Dong ${ }^{3}$, Mingquan $\mathrm{Wu}^{3}$, Gang $\mathrm{Sun}^{3}$ and Quanjun Jiao ${ }^{3}$ \\ 1 Key Laboratory of Digital Earth Science, Aerospace Information Research Institute, \\ Chinese Academy of Sciences, Beijing 100094, China; xingnc@radi.ac.cn \\ 2 College of Resources and Environment, University of Chinese Academy of Sciences, Beijing 100190, China \\ 3 State Key Laboratory of Remote Sensing Science, Aerospace Information Research Institute, Chinese \\ Academy of Sciences, Beijing 100094, China; yehc@radi.ac.cn (H.Y.); dongyy@radi.ac.cn (Y.D.); \\ wumq@radi.ac.cn (M.W.); sungang@radi.ac.cn (G.S.); jiaoqj@radi.ac.cn (Q.J.) \\ 4 Faculty of Science, University of Technology Sydney, Sydney, NSW 2007, Australia; qiaoyun.xie@uts.edu.au \\ 5 School of Computing, Mathematics and Digital Technology, Manchester Metropolitan University, \\ Manchester M1 5GD, UK; shiyue@radi.ac.cn \\ * Correspondence: huangwj@aircas.ac.cn; Tel.: +86-10-8217-8169
}

Received: 13 November 2019; Accepted: 15 December 2019; Published: 18 December 2019

\begin{abstract}
Leaf area index (LAI) is a key parameter in plant growth monitoring. For several decades, vegetation indices-based empirical method has been widely-accepted in LAI retrieval. A growing number of spectral indices have been proposed to tailor LAI estimations, however, saturation effect has long been an obstacle. In this paper, we classify the selected 14 vegetation indices into five groups according to their characteristics. In this study, we proposed a new index for LAI retrieval-transformed triangular vegetation index (TTVI), which replaces NIR and red bands of triangular vegetation index (TVI) into NIR and red-edge bands. All fifteen indices were calculated and analyzed with both hyperspectral and multispectral data. Best-fit models and k-fold cross-validation were conducted. The results showed that TTVI performed the best predictive power of LAI for both hyperspectral and multispectral data, and mitigated the saturation effect. The $\mathrm{R}^{2}$ and RMSE values were $0.60,1.12 ; 0.59$, 1.15 , respectively. Besides, TTVI showed high estimation accuracy for sparse $(\mathrm{LAI}<4)$ and dense canopies $(\mathrm{LAI}>4$ ). Our study provided the value of the Red-edge bands of the Sentinel-2 satellite sensors in crop LAI retrieval, and demonstrated that the new index TTVI is applicable to inverse LAI for both low-to-moderate and moderate-to-high vegetation cover.
\end{abstract}

Keywords: green LAI; red-edge; saturation effect; Sentinel-2; vegetation indices

\section{Introduction}

Leaf area index (LAI) is an essential biophysical parameter in ecological processes. It is defined as half of the leaf area on per unit ground area [1]. LAI is well related with key vegetation parameters like fraction of absorbed photosynthetically active radiation (FAPAR) and leaf chlorophyll content. Therefore, it has been used as an indicator for crop growth monitoring. The usage of LAI goes through the whole growing processes of vegetation. It has been used to monitor crop growth condition and dynamic changes at early growth stages and to estimate crop yield at later growth stages [2]. The living leaves of plants play an important role in photosynthesis, transpiration, and evapotranspiration processes. These functions help understand the exchanges between vegetation and the atmosphere which can better indicate the crop growth condition. Thus, "green LAI," which is denoted as the LAI of living and green leaves, is studied in this research [3]. 
LAI remote sensing retrieval methods have been widely investigated for several decades. During the past years, researchers have conducted studies on different vegetation types like broadleaf forest, coniferous forest and crop including soybean, maize and winter wheat [4-6]. LAI values vary with different vegetation types for different phenology. According to previous studies, LAI retrieval methods can be classified into three groups: (1) Physical methods like radiative transfer model (RTM), PROSPECT, SAIL models which study the physical mechanisms between light and vegetation to describe the light transmission on inner leaf $[7,8]$ or canopy level $[9,10]$; $(2)$ vegetation indices-based empirical methods, which engage on the relationships between spectral reflectance data and biophysical or biochemical parameters using statistical models [11-15]; and (3) the new research frontiers like machine learning methods, including artificial neural network and support vector machine to map LAI on large scales [16-22]. Among these approaches, vegetation indices-based empirical model has been widely used because of its simplicity and computational efficiency.

Crop canopy reflectance is dependent both on biophysical parameters like LAI and biochemical parameters like chlorophyll content [23]. To avoid influence from interfering factors including external factors like atmospheric effect, soil background and intrinsic factors like leaf pigment content, leaf inclination angle, saturation effect, and other structural parameters, substantial efforts were conducted in improving classical VIs and developing new indices. Therefore, indices for different purposes were created. According to the characteristics of the indices, we classified them into five groups as: (a) Indices of normalized difference, (b) indices to improve the linearity, (c) indices of soil-line, (d) indices in the shape of triangular vegetation index, and (e) indices based on the shape of reflectance curves. Healthy vegetation reflect $40-50 \%$ energy in near infrared bands $(700-1000 \mathrm{~nm})$ because of the leaf inner structure, and $10-20 \%$ in visible bands $(400-700 \mathrm{~nm}$ ) because of the chlorophyll absorption in vegetation [24]. The difference of the reflectance in the NIR region and the red region exaggerates the detail information in vegetation. Classical vegetation indices including normalized difference vegetation index (NDVI), simple ratio (SR), and difference vegetation index (DVI) [25-27] take advantages of the reflectance difference between NIR and red region to estimate LAI. Indices like renormalized difference vegetation index (RDVI) [28], modified simple ratio (MSR) [14], and enhanced vegetation index (EVI) [29] were modified indices based on the classical indices to improve linearity with biophysical parameters. Also, LAI estimation can be affected by noise from soil background and atmosphere. Therefore, soil-adjusted vegetation index (SAVI) [11] and optimized soil-adjusted vegetation index (OSAVI) [30] were designed to reduce influence from soil background at low LAI value area. Triangular vegetation index (TVI) [6] was also used widely for several decades and it utilized the area embraced by green peak, the chlorophyll absorption minimum, and the NIR shoulder. To make it more suitable for LAI estimation, modified triangular vegetation index1 (MTVI1) and modified triangular vegetation index2 (MTVI2) [3] were proposed to improve the retrieval accuracy by suppressing the influence from chlorophyll content. Besides, the indices based on the shape of reflectance curve including the linear interpolation of red edge inflection point (REIPlinear) [31] and moment distance index (MDI) [32] take advantage of the abundant wavelengths which are not available from other indices and finally, evaluate the crop dynamics.

Though dozens of vegetation indices were created, an unavoidable problem in the use of these indices arises from the fact that saturation effect has huge impact on LAI estimation. Saturation effect has long been an obstacle in LAI estimation that it decreases estimation accuracy at late growing stages and for high vegetation cover. Many researchers demonstrated that relationships between vegetation indices and leaf area index reached asymptotic at certain conditions. For instance, normalized difference vegetation index (NDVI) was shown to be linearly related with LAI during the leaf production and leaf senescence period but showed no clear relationships for leaf harvest period. The saturation effect decreases inversion accuracy for high vegetation cover which makes it harder to estimate high LAI value. $\mathrm{Li}$ [33] indicated that unsynchronized variance between the leaf area index leads to the saturation effect of normalized difference vegetation index (NDVI). In this case, vegetation indices aimed to mitigate saturation effect has been created like wide dynamic range vegetation index (WDRVI) [34]. 
Moreover, a few VIs with red-edge spectral reflectance were found to be effective to LAI, especially from moderate to high vegetation cover. Red-edge inflection point (REIP) moves toward longer wavelength while leaves grow vigorously and moves back to shorter wavelength under circumstances of water loss and leaves turning yellow and withered [35,36]. The shape of red-edge is strongly influenced by LAI [37,38]. Red-edge VIs were shown to be sensitive to LAI value while insensitive to canopy structure [39]. Red-edge-based indices achieved more accurate LAI estimation than normal indices [20,39]. In this way, red-edge can be regarded as an alternative for LAI estimation.

Therefore, the primary objectives of this research are to: (1) Compare and analyze the performances of vegetation indices of five classes; (2) to propose a vegetation index which helps mitigate saturation effect and improve LAI retrieval accuracy with both hyperspectral and multispectral data.

\section{Materials and Methods}

\subsection{The Study Area}

Winter wheat (Triticum aestivum L.) is a vital crop in the world and also one of the most important cereal crops in northern and southern China. It is planted widely and regularly in China every year which makes China a main wheat-producing country. Knowing the growth condition and yield of winter wheat timely can provide technological suggestions for food security. Thus, winter wheat was used as the research object in this research. Our field experiments were conducted in two study sites (shown in Figure 1). One study site is located at Shunyi District, Beijing, China (116 $31^{\prime} 10^{\prime \prime} \mathrm{E}$ to $116^{\circ} 53^{\prime} 26^{\prime \prime} \mathrm{E}, 40^{\circ} 8^{\prime} 2^{\prime \prime} \mathrm{N}$ to $40^{\circ} 14^{\prime} 0^{\prime \prime} \mathrm{N}$ ), and the other study site is located at Luohe, Henan Province, China $\left(113^{\circ} 52^{\prime} 54^{\prime \prime} \mathrm{E}, 33^{\circ} 42^{\prime} 0^{\prime \prime} \mathrm{N}\right)$. The Shunyi experiment site has a warm temperature climate with an average of $13.8^{\circ} \mathrm{C}$ and annual rainfall of $507.7 \mathrm{~mm}$, and the soil type is silt-clay loam. Field measurements were conducted in 2016 at four main growth stages of winter wheat: tillering stage (7th April), stem elongation stage (20th April), heading stage (3rd May), and milky stage (18th May) during when the leaves were green and active. Twenty-four evenly distributed planting plots with different winter wheat cultivars were selected in the experimental site as sampling units in this study. The Luohe experiment site has a warm temperature climate with an average of $14.6^{\circ} \mathrm{C}$ overlying the loessal sabulous clay. Field measurements were conducted in 2019 at stem elongation stage (22th March) and heading stage (12th April) with six different cultivars. Thirteen sampling plots in $100 \mathrm{~m} \times 50 \mathrm{~m}$ size were selected in Luohe. The winter wheat cultivars included Aikang58, zhoumai27, xinong509, yumai49-198, tianning38, and luomai26.

\subsection{Field Measurements}

\subsubsection{Canopy Spectra Measurements}

Canopy spectrum were collected by ASD FieldSpec spectrometer (Analytical Spectral Devices, Inc., Boulder, CO, USA) in two study sites at multiple growth stages. The spectrometer was configured with a spectral range from $350-2500 \mathrm{~nm}$ with a field of view of $25^{\circ}$. The spectral resolution is $3 \mathrm{~nm}$ between 350-1000 $\mathrm{nm}$ and $10 \mathrm{~nm}$ between 1000-2500 nm. Measurements were taken from a nadir position at the height of $1.3 \mathrm{~m}$ above the ground by averaging 10 repeat scans under sunny hours between 10:00-14:00 (UTC+8). The average spectrum of 5-10 representative points indicates the results of corresponding sampling unit. Reflectance spectra were derived from the calibration by a $40 \mathrm{~cm} \times 40 \mathrm{~cm}$ white reference panel. For vegetation indices calculation, spectra from 400 to $1200 \mathrm{~nm}$ were used because of their comparatively higher sensitiveness and radiometric responses to LAI variation $[6,40,41]$. 


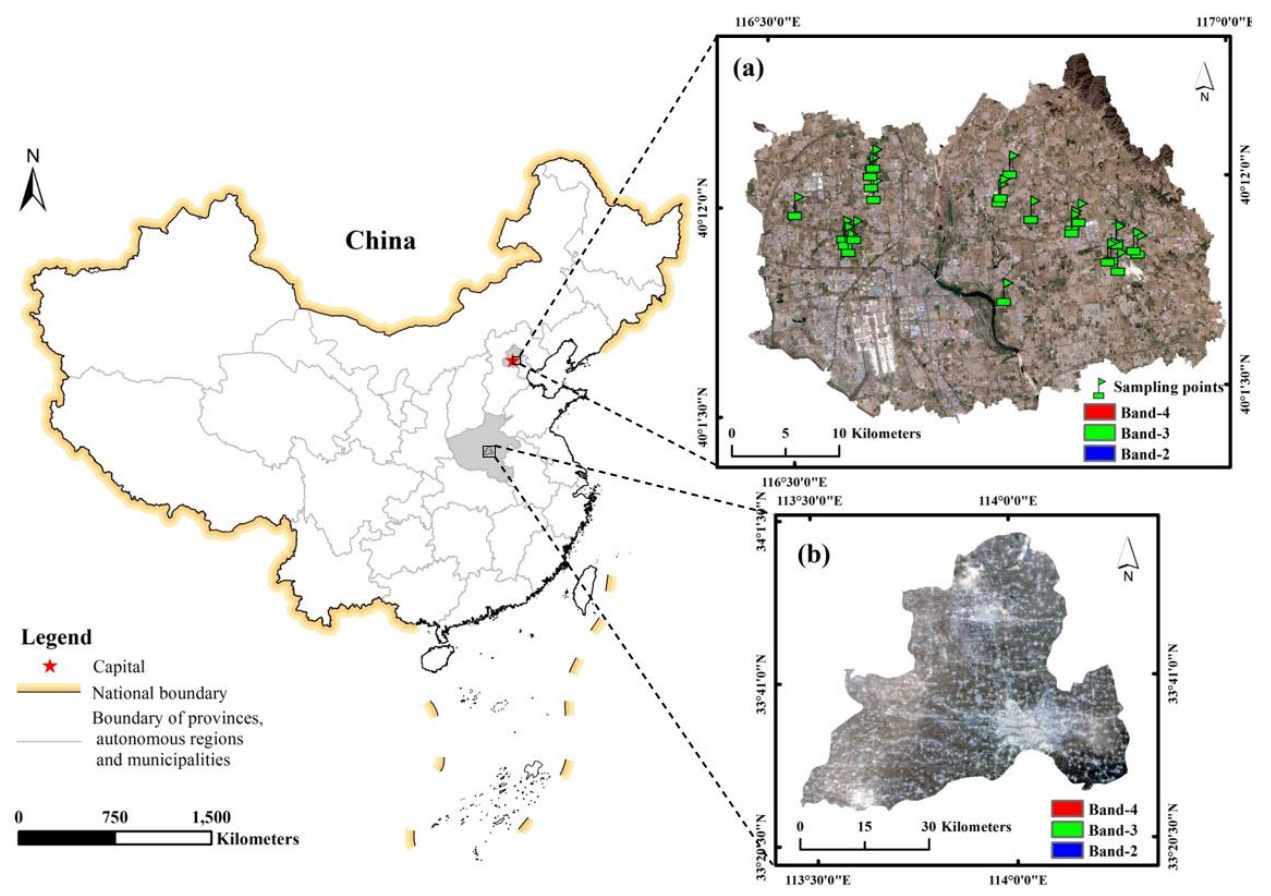

Figure 1. Study sites: (a) Shunyi, Beijing; (b) Luohe, Henan Province.

\subsubsection{Leaf Area Index Acquisition}

LAI measurements were performed by using LAI-2200 plant canopy analyzer (LI-COR Biosciences, Inc., Lincoln, NE, USA). The measurement procedure was based in the equipment manuals. To minimize the measuring error, measurements were conducted during the daytime in bright sunny days and a $45^{\circ}$ cap was used to avoid direct sunlight. To note the results measured by LAI 2200 are effective LAI [42]. LAI value for each sampling unit was obtained as a statistical mean of 15 measures. It includes five date readings (one A value above the canopy and four B values under the canopy) with two replications. The measurement heights are same for four B values. All the data were pooled and used for subsequent analysis.

\subsection{Sentinel-2 Images Acquisition}

In parallel with field measurements, multispectral remote sensing images corresponding to field measurements in two study sites were obtained from the website (https://scihub.copernicus.eu/). Six images were acquired on April 10th and 23th, May 3rd and 18th of 2016, and March 24th and April 13th of 2019. Many researchers have used Sentinel-2 images for agricultural remote sensing and achieved good results in past study [43,44]. Sentinel-2 satellites are part of Global Monitoring for Environment and Security (GMES) programme of the European Space Agency (ESA). The launched satellites include Sentinel-2A and Sentinel-2B. The spatial resolution varies from $10 \mathrm{~m}$ to $60 \mathrm{~m}$ according to specific spectral bands. The satellite has 13 spectral bands ranging from the visible and near-infrared to the short-wave infrared including multiple red-edge bands which have been used widely. Atmospheric correction was conducted by sen2cor which is the special software provided by sentinel official website (http://step.esa.int/main/third-party-plugins-2/sen2cor) freely.

\subsection{Vegetation Indices Selected in This Research}

Fourteen vegetation indices were selected because of their wide use and capabilities in estimating LAI. Based on the specific purposes in LAI retrieval, we classified them into five categories: indices of normalized difference, indices of improving linearity, indices of soil-line, modified indices of triangular vegetation index form and indices based on the shape of reflectance curves. The descriptions and formulas of the fourteen indices were listed in Table 1. 
Table 1. Vegetation indices used for Leaf area index (LAI) estimation in this research.

\begin{tabular}{|c|c|c|c|}
\hline Index & Description & Formula & Reference \\
\hline DVI & Difference vegetation index & $N I R-R$ & [25] \\
\hline SR & Simple ratio & $N I R / R$ & [27] \\
\hline NDVI & $\begin{array}{l}\text { Normalized difference vegetation } \\
\text { index }\end{array}$ & $(N I R-R) /(N I R+R)$ & [26] \\
\hline RDVI & $\begin{array}{l}\text { Renormalized difference } \\
\text { vegetation index }\end{array}$ & $(N I R-R) /(\sqrt{N I R+R})$ & [28] \\
\hline MSR & Modified simple ratio & $\left(\frac{N I R}{R}-1\right) /\left(\sqrt{\frac{N I R}{R}}+1\right)$ & [14] \\
\hline $\begin{array}{l}\text { EVI } \\
\text { SAVI }\end{array}$ & $\begin{array}{l}\text { Enhanced vegetation index } \\
\text { Soil-adjusted vegetation index }\end{array}$ & $\begin{array}{c}G \frac{N I R-R}{N I R+C_{1} R-C_{2} B l u e+L} ; C_{1}=6, C_{2}=7.5, G=2.5, L=1 \\
(1+L) \times(N I R-R) /(N I R+R+L) ; L=0.5\end{array}$ & {$[29]$} \\
\hline OSAVI & $\begin{array}{l}\text { Optimized soil-adjusted } \\
\text { vegetation index }\end{array}$ & $(N I R-R) /(N I R+R+L) ; L=0.16$ & {$[30]$} \\
\hline TVI & Triangular vegetation index & $0.5 \times[120 \times($ NIR - Green $)-200 \times($ Red - Green $)]$ & [6] \\
\hline MTVI1 & $\begin{array}{l}\text { Modified triangular vegetation } \\
\text { index } 1\end{array}$ & $1.2 \times\left[1.2 \times\left(R_{800}-R_{550}\right)-2.5 \times\left(R_{670}-R_{550}\right)\right]$ & [3] \\
\hline MTVI2 & $\begin{array}{l}\text { Modified triangular vegetation } \\
\text { index } 2\end{array}$ & $\frac{1.5 \times\left[1.2 \times\left(R_{800}-R_{550}\right)-2.5 \times\left(R_{670}-R_{550}\right)\right]}{\sqrt{\left(2 \times R_{800}+1\right)^{2}-\left(6 \times R_{800}-5 \times \sqrt{R_{670}}\right)-0.5}}$ & [3] \\
\hline REIP $_{\text {linear }}$ & $\begin{array}{l}\text { The linear interpolation of red } \\
\text { edge inflection point }\end{array}$ & $\begin{array}{c}700+40\left[\frac{R_{\text {red-edge }}-R_{700}}{R_{740}-R_{700}}\right] \\
R_{\text {red-edge }}=\left(R_{670}-R_{780}\right) / 2 \\
M D_{R P}-M D_{L P}\end{array}$ & [31] \\
\hline MDI & Moment distance index & $\begin{aligned} M D_{L P} & =\sum_{i=\lambda_{L P}}^{\lambda_{R P}}\left(\rho_{i}{ }^{2}+\left(i-\lambda_{L P}\right)^{2}\right)^{0.5} \\
M D_{R P} & =\sum_{i=\lambda_{R P}}^{\lambda_{L P}}\left(\rho_{i}{ }^{2}+\left(\lambda_{R P}-i\right)^{2}\right)^{0.5}\end{aligned}$ & [32] \\
\hline
\end{tabular}

\subsubsection{Vegetation Indices of Normalized Difference}

The reflectance difference between NIR and red spectral region has provided basis for designing vegetation indices. Indices based on the combination of NIR and red bands are selected because of their ubiquitous usage in crop biophysical parameters retrieval.

DVI is the difference between NIR and red reflectance [25]. It is sensitive to the change of soil background which is helpful for environment monitoring. SR compares the signal between NIR and red reflectance [27]. The ratio-formed index can fully indicate the difference of the two bands. To exaggerate the contrast between the maximum absorption in the red reflectance and the maximum reflection in the infrared reflectance, NDVI combined the advantages of DVI and SR [26]. It is the most known vegetation index and plays a role as benchmark in LAI retrieval. It takes advantage of the red absorption valley and NIR reflectance peak to obtain growth condition such as water content and vegetation cover. NDVI was used in this study because of its wide-acknowledged relation with LAI $[45,46]$. The ratio form can partly reduce the influence of irradiance changes from the solar elevation angle, cloud, shadow, and atmospheric status. It reduces the influence from soil background and exaggerates the reflectance between near infrared band and red band. However, these indices strengthen the low value and weaken the high value. Thus, it leads to saturation effect at high vegetation cover.

\subsubsection{Vegetation Indices of Improving the Linearity}

RDVI, MSR, and EVI are the indices created to improve linearity and eliminate saturation effects. They are transforms of classical indices such as NDVI and SR. RDVI was designed to linearize the relationships with vegetation biophysical parameters [28]. MSR was considered to be more linearly related to vegetation parameters [28]. It was designed to linearize the relationship with biophysical parameters and to overcome saturation effect of NDVI [14]. EVI was suggested to have better relationship with vegetation parameters in high vegetation cover while minimizing soil and atmosphere influences.

RDVI and MSR both use NIR and red regions; whereas MSR is more influenced by chlorophyll content because of the ratio of NIR and red which is highly correlated to chlorophyll content [3]. MSR and SR presented similar trends with LAI. However, MSR had a slightly better resistance because of the adjustment factor in the index compared with SR. 


\subsubsection{Vegetation Indices of Soil-Line}

To reduce the influence from soil background, soil-adjusted indices were developed. Indices based on soil-line are created to improve the resistance to soil contamination effects and atmospheric effects and minimize the background influence [3]. SAVI was the leading index of soil-adjusted indices to account for changes in the soil optical properties. It decreases the soil noise better than NDVI without being sensitive to high value LAI [11]. OSAVI relies on the basic form of SAVI and made a little progress in the equation and factor of $\mathrm{L}$ so that it can get better retrieval accuracy and eliminates the impacts from soil background. Both SAVI and OSAVI are designed to justify the impacts from soil background and decrease the sensitiveness of NDVI [30].

\subsubsection{Vegetation Indices of Triangular Form}

The general idea of TVI is based on the triangular area encircled by green peak, near-infrared shoulders, and chlorophyll absorption minimum. It described the radiative energy absorbed by the pigments [6]. The triangular area will increase as a result of chlorophyll absorption (decrease of red reflectance) and leaf tissue abundance (increase of NIR reflectance). In this way, TVI capture variations more than just LAI. The increase of chlorophyll content can bring an increase to triangle area which may bring uncertainties in LAI retrieval [3]. Modified triangular vegetation index like MTVI1 and MTVI2 were created based on TVI replaced with soil adjustment factors [3]. MTVI1 replaced the NIR reflectance $750 \mathrm{~nm}$ with $800 \mathrm{~nm}$ which is insensitive to pigment level changes. And a soil adjustment factor was incorporated to reduce contamination effects in MTVI2. It is found that MTVI2 is resistant to soil background and leaf chlorophyll content. MTVI2 has been found to remain sensitive to LAI for high vegetation cover than other indices.

\subsubsection{Vegetation Indices Based on the Shapes of the Reflectance Curves}

Apart from the four common groups mentioned above, an innovative index group based on the shape of reflectance curve takes advantage of the information latent in the shape of the reflectance curve that is not available from other spectral indices [32]. Different from current indices, these indices incorporate more than two or three bands which enable them to carry more useful information. Besides, these indices were mathematically simple but powerful without any curve transformation. [32]. In this way, the linear interpolation of red edge inflection point (REIPlinear) and moment distance index (MDI), as two representatives of the group were used in the research.

\subsection{New Vegetation Index Proposed in This Research}

To improve LAI retrieval accuracy, a modified vegetation index denoted as transformed triangular vegetation index (TTVI) was proposed in this study. The index aims to improve retrieval accuracy by improving linearity with LAI and eliminating saturation effect. The general idea of the modification is to render the index more sensitive to LAI variation and resistant to other interference factors.

It can be seen both from Table 1 and previous literature that visible and NIR bands are widely used in spectral indices. Visible and NIR region are both correlated with LAI. NIR region has been used for a long time in estimating vegetation parameters. NIR shoulder is sensitive to LAI variation and the reflectance increases with the rising of LAI value. The scattering of multi layers of leaves leads to an increase in NIR reflectance. More leaves lead to more scattering and result in a higher NIR reflectance. Higher reflectance at NIR region will cause the increase of the triangular area which is helpful for estimating LAI. The increase of LAI value leads to the higher reflectance in NIR region. Thus, NIR is the key spectral region in LAI retrieval. This response can be capitalized on to estimate LAI value. However, leaf reflectance in the 400-700 nm wavelength interval is influenced primarily by the pigments chlorophyll and carotenoid $[47,48]$. To avoid noise from interfering factors and adverse variation to LAI, the usage of visible wavelength needs to be decreased. Studies have shown that red-edge position is well correlated with biophysical parameters at canopy level [6]. Besides, the 
red-edge is less sensitive to soil background and atmospheric effects and can provide information, not available from a combination of near infrared and visible spectral bands $[49,50]$. Therefore, spectral bands in red-edge and NIR regions can be good choices to formulate vegetation indices. For growth stages used in this research (tillering stage, stem elongation stage, heading stage, and milky stage), red-edge inflection point (REIP, calculated by first derivate spectrum) is not fixed. We take red-edge bands settings of satellites including Sentinel-2, Worldview-2, and RapidEye into consideration to select a suitable red-edge wavelength. We selected the suitable red-edge and NIR bands by comparing the $\mathrm{R}^{2}$ and RMSE between spectral reflectance and LAI (not shown in the paper). The $740 \mathrm{~nm}$ turned out to have the best performance of red-edge region. It is also an intersection for reflectance of various different growth stages in this study. The $783 \mathrm{~nm}$ and $865 \mathrm{~nm}$ were chosen as NIR shoulder.

The area of triangular is calculated based on the concept of determinant. TTVI is defined as the area encircled by triangular ABC with the specific coordinates given in spectral space:

$$
S_{\Delta}=0.5 \times|\operatorname{det}(A C, A B)|=0.5 \times\left|\begin{array}{cc}
\lambda_{C}-\lambda_{A} & R_{C}-R_{A} \\
\lambda_{B}-\lambda_{A} & R_{B}-R_{A}
\end{array}\right|
$$

where $\mathrm{A}, \mathrm{B}$, and $\mathrm{C}$ are three vertices of the triangle, $\lambda_{i}$ indicates the wavelengths and $R_{i}$ is the reflectance of three vertices.

$$
\begin{aligned}
& \text { TTVI }=0.5 \times\left[(865-740) \times\left(R \_783-R \_740\right)-\left(R \_865-R \_740\right) \times(783-740)\right] \\
& \quad=0.5 \times\left[(783-740) \times\left(R \_865-R \_740\right)-(865-740) \times\left(R \_783-R \_740\right)\right]
\end{aligned}
$$

The orders of bands affect whether the results are positive or negative. To acquire positive results, we calculated in the order of $A C$ and $A B$, where $A=(740 \mathrm{~nm}, \mathrm{R} 740), \mathrm{B}=(783 \mathrm{~nm}, \mathrm{R} 783)$, and $C=$ (865 nm, R865). R740, R783, R865 indicate the reflectance of 740, 783, and $865 \mathrm{~nm}$ for hyperspectral sensors and indicate the central wavelength of band 6, band 7 and band 8A from Sentienl-2 MSI sensors, respectively.

The general idea of the triangular vegetation index (TTVI) is the area of the triangular embraced by red-edge bands and NIR bands as shown in Figure 2. It is based on the fact that both increased NIR reflectance caused by leaf tissue abundance and red-edge shift will lead to an increase of the total area of the triangular. Compared to existing TVI and its modified indices, the new index follows the similar triangular form, but different in the specific wavelength selection. The combination of NIR shoulder and red-edge spectral reflectance helps avoid the chlorophyll content sensitive region to mitigate influence from chlorophyll content. Triangular area is mainly affected by NIR shoulder. Moreover, the red-edge band makes it more resistant from soil and atmospheric influence. These characteristics indicate that the new index is promising to estimate LAI; therefore, it was further used in this study.

In order to make the index capable for satellite and able to inverse LAI at large scale, we replaced hyperspectral bands with corresponding Sentinel-2 multispectral bands.

\subsection{Indices Calculation and Statistics Analysis}

For hyperspectral vegetation indices whose reflectance was not clearly stated, correlations between LAI and wavelengths were calculated. For all the growth stages, the best correlation appeared in NIR and red band region. Best related wavelengths in NIR (740-1100 nm) band and red band (600-740 nm) were selected by Matlab R2013b (The Math Works, Inc., Natick, MA, USA). That turned out to be 665 $\mathrm{nm}$ for red spectral region and $887 \mathrm{~nm}$ for near infrared spectral region.

Field measured hyperspectral spectrum and Sentinel-2 reflectance were used in this part. Field measured reflectance were used to build the LAI retrieval models and to compare the linearity between LAI and indices. Sentinel-2 data were used to test the robustness of the LAI retrieval model.

A hundred and fifty records were analyzed in this research. To analyze the relationship between indices and LAI, best-fit models are used in this research. Best-fit models between vegetation indices and LAI were obtained based on mathematic characteristics of indices [4]. Both linear and non-linear 
regression models were used to fit LAI and indices. All 150 records were divided into a training dataset $(66.7 \%)$ and a validation dataset $(33.3 \%)$ using stratified random sampling to make sure LAI values cover the range of 0 to 8 . For model validation, the $\mathrm{k}$-fold cross validation procedure was used in both hyperspectral and multispectral dataset to evaluate the performance of vegetation indices. The data were randomly split into $k=5$ sets, four of which were used iteratively for calibration and the rest set for validation [51]. This method ensures each dataset is used and only used once which avoids systematic errors. Coefficient of determination $\left(\mathrm{R}^{2}\right)$, root mean square error (RMSE), and mean absolute error (MAE) are used as indicators to evaluate the retrieval accuracy of the vegetation indices. $\mathrm{R}^{2}$ was used to indicate the fitness of regression model and RMSE was used to compare the predictive performances of indices. Significant test was conducted to validate the reliability of the regression results. $p$-Values were used to evaluate the significance level. The data processing and statistical analyses procedures were performed by Matlab R2013b (The Math Works, Inc., Natick, MA, USA).

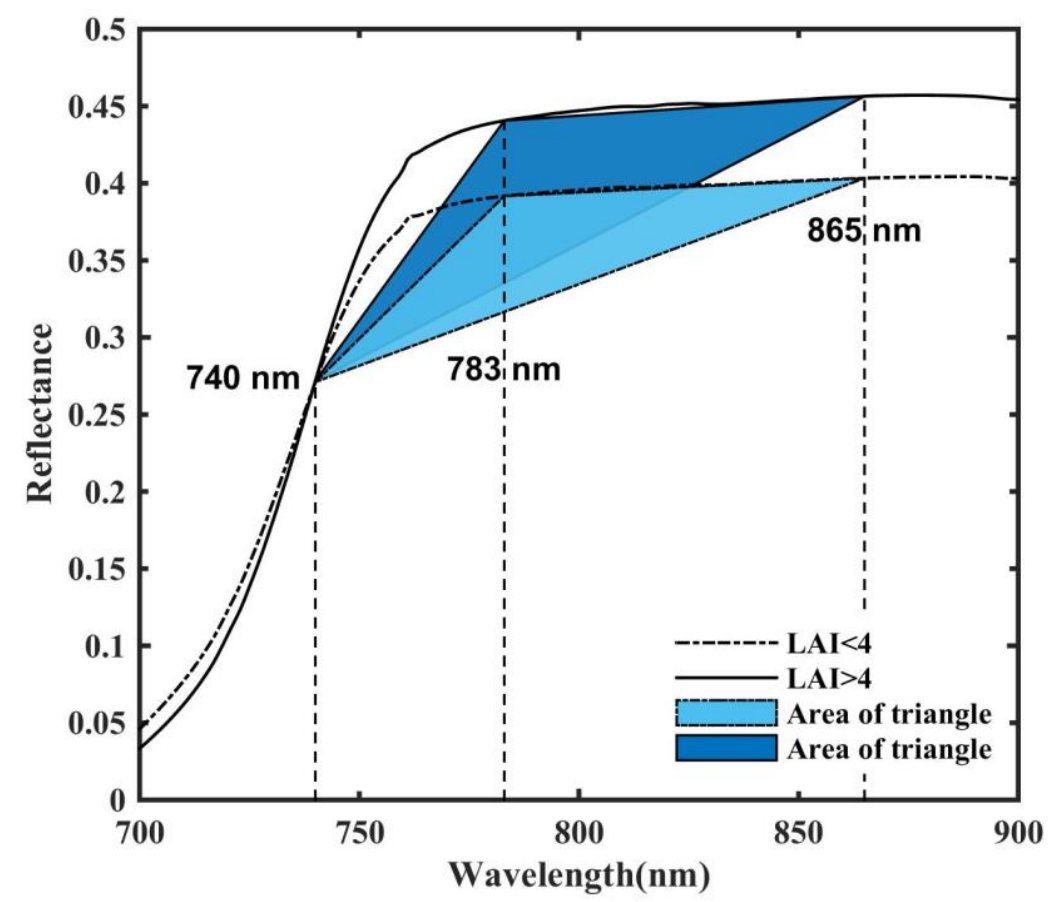

Figure 2. Triangular area of transformed triangular vegetation index (TTVI) for LAI lower than 4 and LAI greater than 4 .

\section{Results}

\subsection{Relationship between VIs and LAI Using Field Measured ASD Data}

The relationships between VI and LAI are not fixed because of interfering factors such as chlorophyll content and saturation effect. To further compare and assess the abilities of various indices in estimating LAI, field measured hyperspectral reflectance were used to calculate the relationships between indices and LAI. Linear relationships were expected to mitigate saturation effect especially in high LAI value region. As can be seen from Figure 3, most indices behave nonlinearly rather than linearly with LAI. This remain consistent with previous studies [3]. The indices value increased slowly when LAI reached a high value compared to the low LAI value. 

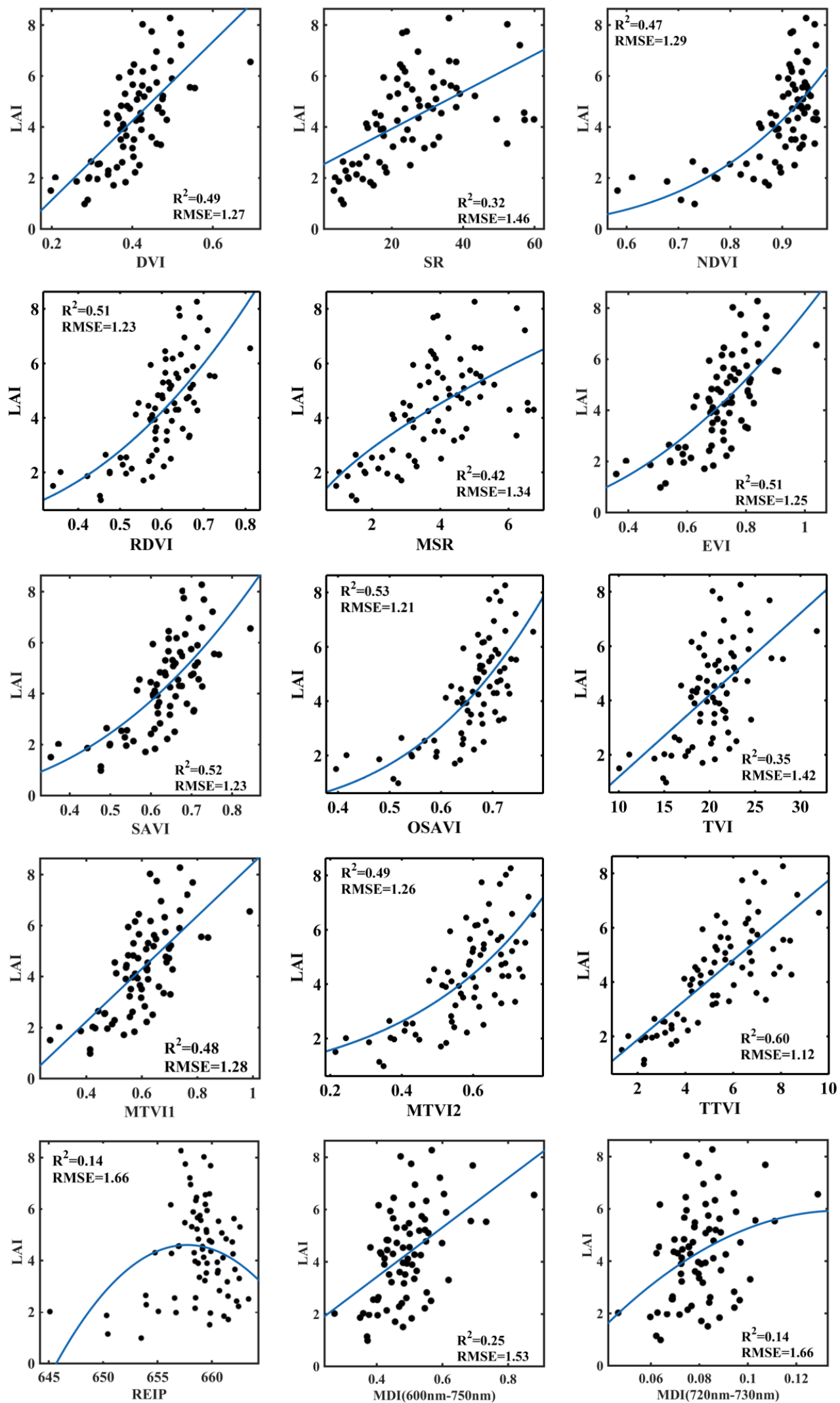

Figure 3. Relationships between vegetation indices and LAI using field measured ASD data.

According to the performances of indices in LAI retrieval, we grouped these indices into five classes. For DVI, SR, and NDVI, the relationships with LAI were not clear. SR showed a relatively low 
$\mathrm{R}^{2}$ of 0.3238 and a RMSE of 1.457. Plots reached a saturation level with LAI greater than 4 for NDVI. NDVI exhibited obvious exponential trend for different LAI values. It ranged from 0.55 to 0.90 for LAI from 0 to 2 and roared fast when LAI is greater than 4. NDVI is obviously influenced by saturation effect. The reason may be concluded to the reverse variation of NIR and red spectral reflectance with the increase of LAI. With the increase of LAI, NIR reflectance increases whereas red spectral reflectance first decreases and then reaches an asymptote when LAI is greater than 4 [20]. MSR, RDVI, and EVI performed better as modifications than their corresponding original indices with higher $\mathrm{R}^{2}$ and lower RMSE. They exhibited less scattering with the fitted lines. Both MSR and SR presented a substantial dispersion of their values. The results are identical to previous study which indicated the ratio of NIR and red wavelengths are sensitive to chlorophyll content. Thus, they are not good estimates of green LAI [3]. Indices aimed to eliminate soil background effect as SAVI and OSAVI showed good relationships with LAI. They have similar $\mathrm{R}^{2}$ and RMSE and almost same scattered plots because of their common goal of suppressing influence from soil background. OSAVI overwhelmed SAVI with higher $R^{2}$ and lower RMSE $\left(R^{2}=0.53\right.$ and RMSE $=1.21$ for OSAVI; $R^{2}=0.52$ and RMSE $=1.23$ for SAVI) but the unevenly distribution of plots of OSAVI is obvious. For LAI lower than 4, OSAVI varied from 0.4 to 0.6 , while the OSAVI value cluster around 0.7 when LAI rose from 4 to 8 . For indices in the shape of triangular area, the performances were quite different. The best-fit models for TVI and MTVI1 turned out to be linear models in this study, while, MTVI2 showed exponential correlation with LAI. For TVI, its relationship with LAI was poor $\left(\mathrm{R}^{2}=0.35\right.$, RMSE $\left.=1.42\right)$. The scatterplots of TVI versus LAI exhibited dispersion especially when LAI exceeded 4 . The sensitivity of TVI to chlorophyll content increases with the increase of canopy density. Compared to TVI, MTVI1, and MTVI2 were more sensitive to LAI variation. MTVI1 and MTVI2 replaced original wavelengths with longer NIR wavelength to avoid the influence caused by chlorophyll content increase. MTVI1 and MTVI2 had the $\mathrm{R}^{2}$ of 0.48 and 0.49 , separately. MTVI2 exhibited a better retrieval performance and less scattering because of the soil adjustment factor which was optimized with the constraint of preserving the sensitivity to LAI as well as the insensitiveness to chlorophyll influence. Though MTVI2 made progress in resistance to chlorophyll content, the relationship between MTVI2 and LAI remained to be nonlinear. MTVI1 and MTVI2 showed better retrieval results than the original triangular index. The indices based on the shape of reflectance curves did not perform well for ASD data. It is difficult to find a proper fitting model for the scattering plots. It also can be seen in Figure 3 that REIPlinear, MDI $(600-750 \mathrm{~nm})$, and MDI $(720-730 \mathrm{~nm})$ exhibited a poor relationship with LAI. The results are consistent with the previous studies that REIP was not sensitive to LAI variations [31]. The estimation abilities of MDI (600-750 nm) and MDI (720-730 nm) were limited. Possible reasons might be that MDI was designed to estimate chlorophyll content and not sensitive to LAI. In general, TTVI turned out to be the best index to estimate LAI using ASD data. Though there is a dispersion at high LAI for TTVI, the sampling scattering plots distributed evenly to the both sides of the fitted line. The variation of LAI and TTVI is simultaneous. TTVI performed a linear relationship with LAI with the highest $\mathrm{R}^{2}$ and the lowest RMSE among all 15 vegetation indices $\left(R^{2}=0.60\right.$, RMSE $\left.=1.12\right)$. As can be seen in Figure 3 , plots are closer to fitted line of TTVI.

Relationships between LAI and vegetation indices show several features: (1) Vegetation indices showed saturation effects when LAI is over 4, (2) for LAI greater than 4, indices including NDVI, RDVI, EVI, SAVI, and OSAVI exhibited a dense distribution.

K-fold cross validation was processed to evaluate the predictive power of spectral indices with ASD data. To compare the performances of indices clearly, we ranked the indices by their $\mathrm{R}^{2}$ and RMSE. As can be seen from Table 2, the $\mathrm{R}^{2}$ and RMSE for the same index slightly varied with the change of LAI value. TTVI showed the best performance with the highest $R^{2}$ value of 0.62 and the second lowest RMSE value of 1.28 only higher than that of EVI. MTVI2 remained to have a strong correlation with LAI of $R^{2}$ value of 0.60 , RMSE value of 1.82 . SR was not well correlated with LAI with the lowest $R^{2}$ value of 0.39 and a relatively high RMSE value of 1.59 . TVI showed a better performance with validation data. It increased $\mathrm{R}^{2}$ value from 0.35 to 0.59 and decreased RMSE from 1.42 to 1.32 . The 
other indices including DVI, NADVI, RDVI, EVI, SAVI, OSAVI MTVI1 performed similar R ${ }^{2}$ and RMSE. The indices based on shape of reflectance curves did not show good estimation for LAI. REIPlinear and MDI (720-730 $\mathrm{nm})$ did not pass the significant test.

Table 2. Cross-validation results for LAI assessment with field ASD data $(n=38)$.

\begin{tabular}{cccccc}
\hline Index & Rank & $\mathbf{R}^{\mathbf{2}}$ & RMSE & MAE & $p$-Value \\
\hline DVI & 8 & 0.57 & 1.41 & 1.17 & $* *$ \\
SR & 12 & 0.39 & 1.59 & 1.32 & $* *$ \\
NDVI & 10 & 0.56 & 2.06 & 1.75 & $*$ \\
RDVI & 4 & 0.60 & 1.60 & 1.30 & $*$ \\
MSR & 11 & 0.49 & 1.83 & 1.48 & $*$ \\
EVI & 3 & 0.60 & 1.12 & 0.95 & $*$ \\
SAVI & 6 & 0.59 & 1.61 & 1.30 & $*$ \\
OSAVI & 9 & 0.57 & 4.43 & 4.16 & $*$ \\
TVI & 5 & 0.59 & 1.32 & 1.09 & $*$ \\
MTVI1 & 7 & 0.58 & 1.36 & 1.15 & $*$ \\
MTVI2 & 2 & 0.60 & 1.82 & 1.51 & * \\
TTVI & 1 & 0.62 & 1.28 & 1.10 & $*$ \\
REIPlinear & 14 & 0.07 & 1.63 & 1.34 & Not significant \\
MDI(600-750 nm) & 13 & 0.19 & 1.78 & 1.49 & Not significant \\
MDI(720-730 nm) & 15 & 0.004 & 1.75 & 1.42 & $*$ means $p$-Value $<0.001$.
\end{tabular}

According to the results above, the best behavior considering both resistance to saturation effect and responsiveness to LAI variation with hyperspectral remote sensing data is given by TTVI.

\subsection{Relationship between VIs and LAI Using Sentinel-2 Data}

To assess the differences and validate the estimation in vegetation indices behavior, we extracted spectral reflectance in Sentinel-2 images during 2016 and 2019 at two study sites and calculated the relationships between LAI and indices derived from Sentinel-2 images. The results can be seen from Figures 4 and 5 and Table 3.

Table 3. Cross-validation results for LAI assessment using Sentinel-2 data $(n=38)$.

\begin{tabular}{cccccc}
\hline Index & Rank & $\mathbf{R}^{\mathbf{2}}$ & RMSE & MAE & $p$-Value \\
\hline DVI & 10 & 0.43 & 1.30 & 1.10 & $*$ \\
SR & 11 & 0.39 & 1.28 & 1.08 & $*$ \\
NDVI & 4 & 0.51 & 1.21 & 1.02 & $*$ \\
RDVI & 8 & 0.44 & 1.29 & 1.06 & $*$ \\
MSR & 13 & 0.36 & 1.31 & 1.10 & $*$ \\
EVI & 2 & 0.55 & 1.16 & 0.93 & $*$ \\
SAVI & 12 & 0.38 & 1.39 & 1.15 & $*$ \\
OSAVI & 6 & 0.47 & 1.25 & 1.04 & $*$ \\
TVI & 3 & 0.52 & 1.22 & 1.02 & $*$ \\
MTVI1 & 5 & 0.49 & 1.26 & 1.08 & $*$ \\
MTVI2 & 7 & 0.47 & 1.28 & 1.08 & $*$ \\
TTVI & 1 & 0.59 & 1.15 & 0.99 & $* *$ \\
REIPlinear & 9 & 0.44 & 1.22 & 0.98 & $* * *$ \\
MDI (600-750 nm) & 15 & 0.24 & 1.43 & 1.17 & $*$ \\
MDI (720-730 nm) & 14 & 0.27 & 1.42 & 1.15 & $* * *$ \\
\hline
\end{tabular}

Note: ${ }^{*}$ means $p$-Value $<0.05,{ }^{* *}$ means $p$-Value $<0.01,{ }^{* * *}$ means $p$-Value $<0.001$. 

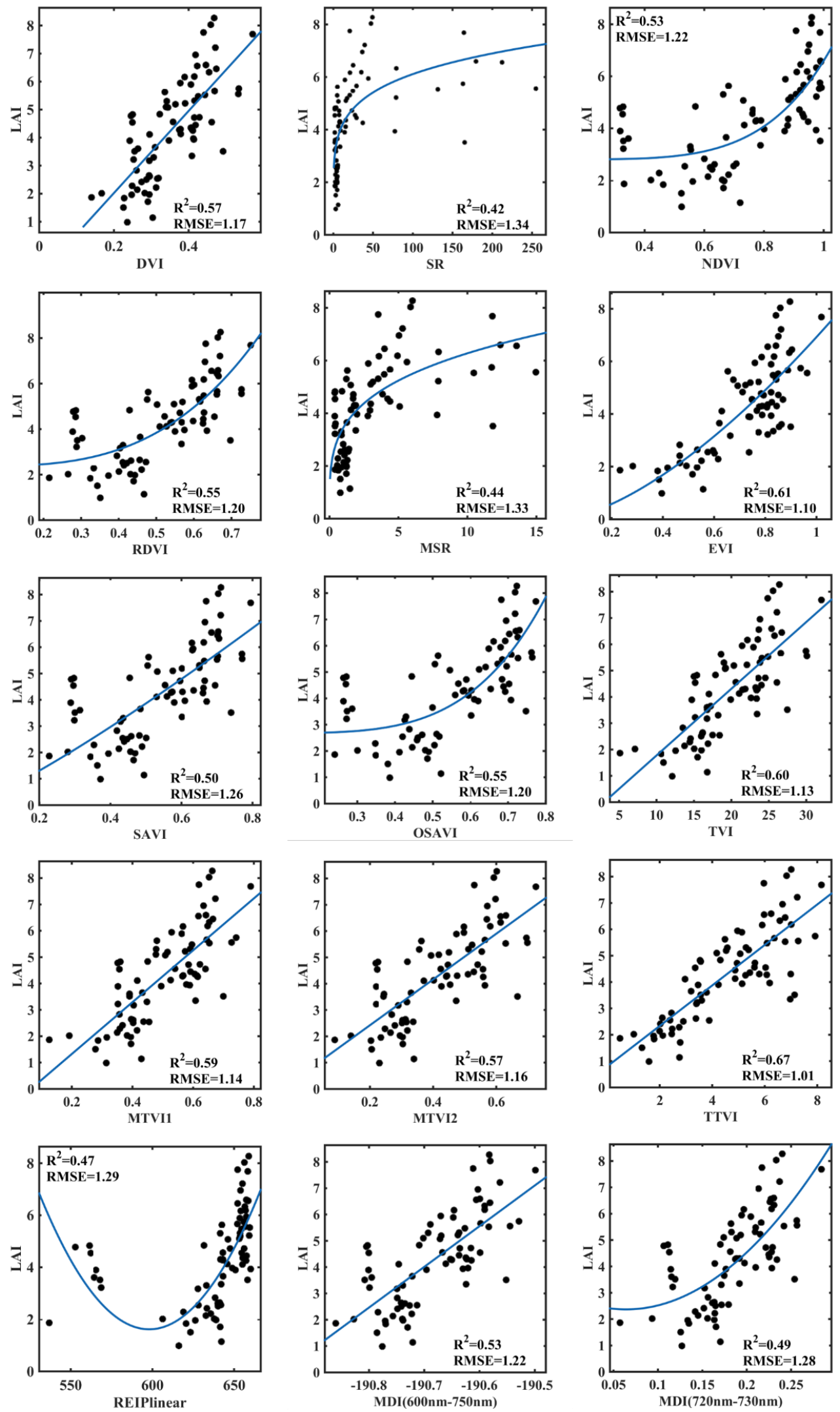

Figure 4. Relationships between vegetation indices and LAI using Sentinel-2 data. 

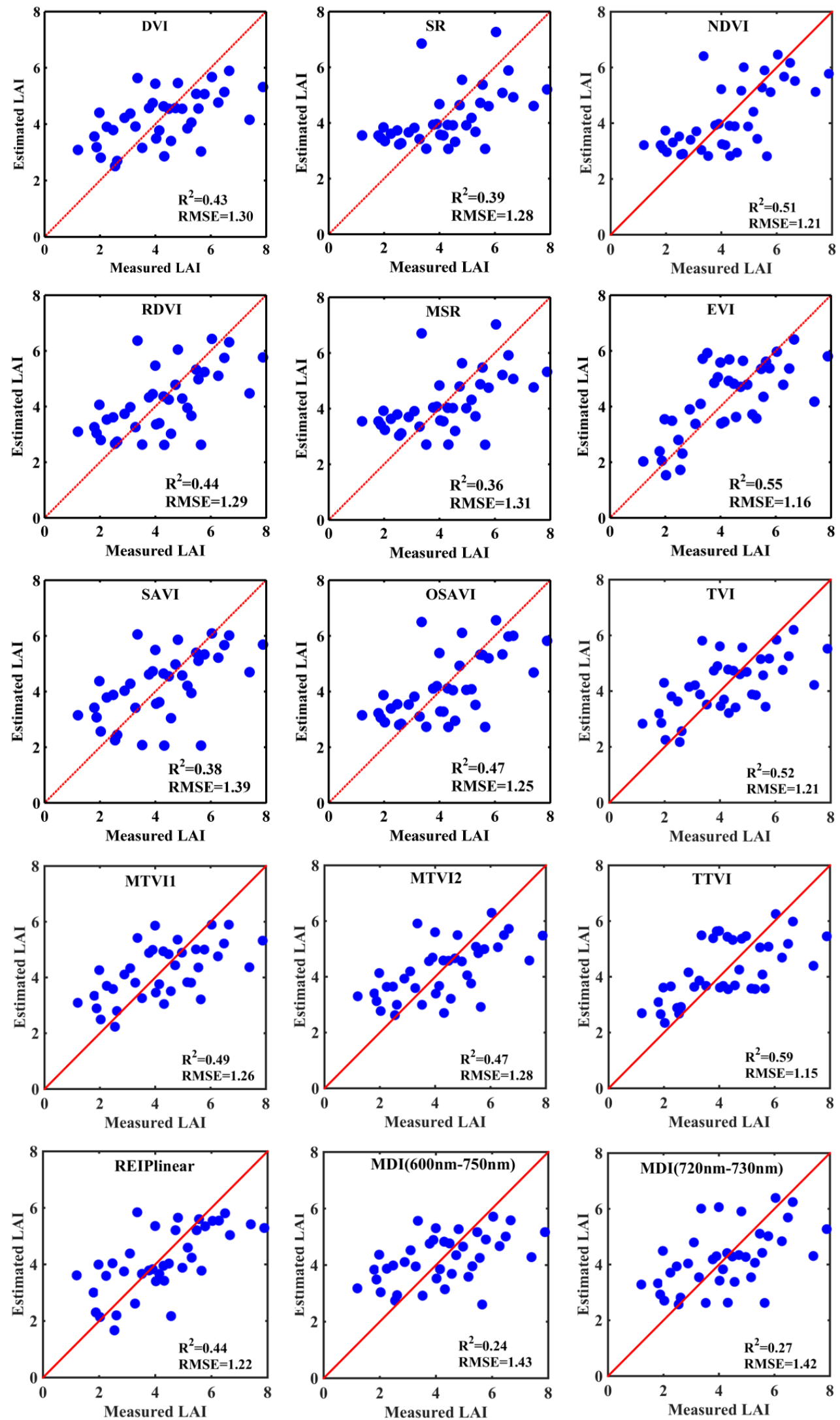

Figure 5. Scatterplots of measured LAI versus estimated LAI for vegetation indices with Sentinel-2 data. Red dashed lines indicated 1:1 lines. 
The $\mathrm{R}^{2}$ and RMSE calculated in Figure 4 had an obvious increase compared to those in Figure 3 in general. Similar results have been demonstrated in previous studies that different indices data sources have distinctive relationships with LAI derived from experiments on NDVI for deciduous forest [52]. Indices including EVI, TVI, TTVI, MDI (600-750 nm) and MDI (720 and $730 \mathrm{~nm})$ performed much better than their counterparts calculated by ASD data. EVI, TVI, and TTVI showed strong relationships with LAI with $\mathrm{R}^{2}$ value of $0.61,0.60$, and 0.67 , respectively. For DVI, SR, and NDVI, the performances were quite different. DVI showed better estimation; SR showed evident clustering at low LAI and dispersion at high LAI and had a limited dynamic; NDVI showed dispersion for both high and low LAI. For RDVI and MSR, dispersion still existed. SAVI and OSAVI behaved similarly with dispersion at low LAI. For indices based on the form of triangular vegetation index, the performances were better with higher $\mathrm{R}^{2}$ and lower RMSE compared to other groups. TVI and MTVI1 seems to be less sensitive to the saturation phenomena which leads to similar results with previous research [3]. For indices based on the shape of reflectance curve, they performed much better relationships with LAI than in Figure 3. The spectral resolution difference between hyperspectral data and multispectral data might be responsible for the variation. TTVI had the highest $\mathrm{R}^{2}$ among all the indices used in this paper. It exhibited the relationship both with low LAI and high LAI. The fitted line was closer to one which indicates the linear relationship between LAI and TTVI is clear. This linearity enables TTVI varies simultaneously with the changes of LAI values. The higher LAI were not good as lower LAI because of some dispersion. To study further, these dispersions can be concluded to the random dataset. All the data were selected randomly using Matlab code as shown in Section 2.6.

The validation results between estimated LAI and measured LAI are shown in Figure 5. The results were slightly worse than those from hyperspectral data. For both NDVI and SR, saturation effect remained to be an obstacle in LAI retrieval. They underestimated high LAI (LAI > 4) and overestimated low LAI (LAI < 4). The results are constant with previous research works [53]. For DVI, RDVI, EVI, SAVI, OSAVI, TVI, MTVI1, and MTVI2, performances were similar. For RDVI, MSR, and EVI, the relationships were better. EVI seems to have a better estimation with the $\mathrm{R}^{2}$ value of 0.55 and RMSE of 1.16. To be noticed that SR and MSR had diverse relationships with LAI compared to other indices. Correlations between estimated LAI and measured LAI do not fit the 1:1 line obviously. SR showed low accuracy for LAI assessment with $\mathrm{R}^{2}$ of 0.39 and RMSE of 1.28. The performances of SAVI and OSAVI seem to be worse than that with hyperspectral data. SAVI showed a low correlation with LAI particularly. The scattered plots distributed far from the fitted line. For indices based on the form of triangular area, MTVI2 performed a better prediction for LAI. The scattering plots of triangular form including TVI, MTVI1, and MTVI2 showed similar trends with LAI and performed better than above mentioned indices but the scatterplots of TVI and MTVI1 exhibited large dispersion. This result is consistent with that in both field measured data. Statistics revealed that TTVI showed a consistently good prediction of LAI for winter wheat with the highest $\mathrm{R}^{2}$ and the lowest $\mathrm{RMSE}\left(\mathrm{R}^{2}=0.59, \mathrm{RMSE}\right.$ $=1.15$ ) compared to other indices. It improved $\mathrm{R}^{2}$ accuracy by $7.0 \%$ compared to MSR and $64.7 \%$ compared to EVI. It also decreased RMSE from 1.39 to 1.15 compared to other indices. The fitted line was closer to the 1:1 line. TVI and EVI also showed good performances, but TVI had a dispersion for low LAI which can decrease the retrieval accuracy; besides, blue band is needed for EVI which makes it convenient to calculate. For both hyperspectral and multispectral remote sensing datasets, TTVI remained linearly related to LAI. This indicates the estimation capability of TTVI for both data sources. In general, TTVI is the best index among all the 15 vegetation indices.

\subsection{Possibility of Mitigating Saturation Effect with LAI}

The results derived from Figures 4 and 5 are consistent with the previous studies [33], relationships between LAI and indices made changes at LAI value of 4 . To better evaluate the ability to mitigate saturation effect of the existing indices and the new index, we analyzed the relationships between indices and LAI value of less than 4 and greater than 4 respectively with their best-fit models. To achieve a sufficient utilization of training data, a cross-validation with $\mathrm{k}$ of 5 was used to evaluate 
performances with LAI. Table 4 shows the best results chosen from 1000 iterations. Indices showed distinct performances in two classes. Most the indices pass the t-test at the significant level with $p$-Value lower than 0.001 .

Table 4. Relationships between LAI and indices for LAI under different values.

\begin{tabular}{|c|c|c|c|c|c|c|}
\hline \multirow{2}{*}{ Index } & \multicolumn{2}{|c|}{ LAI $<4$} & \multicolumn{4}{|c|}{ LAI $>4$} \\
\hline & $\mathbf{R}^{2}$ & RMSE & $p$-Value & $\mathbf{R}^{2}$ & RMSE & $p$-Value \\
\hline DVI & 0.52 & 0.49 & $* * *$ & 0.35 & 0.86 & $* * *$ \\
\hline SR & 0.58 & 0.46 & $* * *$ & 0.21 & 0.96 & * \\
\hline NDVI & 0.52 & 0.49 & $* * *$ & 0.23 & 0.94 & $* *$ \\
\hline RDVI & 0.54 & 0.48 & $* * *$ & 0.38 & 0.84 & $* * *$ \\
\hline MSR & 0.58 & 0.46 & $* * *$ & 0.22 & 0.95 & $* *$ \\
\hline EVI & 0.50 & 0.50 & $* * *$ & 0.38 & 0.84 & $* * *$ \\
\hline SAVI & 0.54 & 0.48 & $* * *$ & 0.40 & 0.83 & $* * *$ \\
\hline OSAVI & 0.54 & 0.48 & $* * *$ & 0.40 & 0.83 & $* * *$ \\
\hline TVI & 0.40 & 0.55 & $* *$ & 0.26 & 0.92 & $* *$ \\
\hline MTVI1 & 0.50 & 0.50 & $* * *$ & 0.35 & 0.87 & $* * *$ \\
\hline MTVI2 & 0.55 & 0.48 & $* * *$ & 0.38 & 0.84 & $* * *$ \\
\hline TTVI & 0.78 & 0.33 & $* * *$ & 0.50 & 0.76 & $* * *$ \\
\hline REIPlinear & 0.27 & 0.63 & $* *$ & 0.26 & 0.92 & $* *$ \\
\hline $\operatorname{MDI}(600-750 \mathrm{~nm})$ & 0.50 & 0.52 & $* * *$ & 0.42 & 0.81 & $* * *$ \\
\hline $\operatorname{MDI}(720-730 \mathrm{~nm})$ & 0.48 & 0.53 & $* * *$ & 0.36 & 0.86 & $* * *$ \\
\hline
\end{tabular}

The $\mathrm{R}^{2}$ and RMSE of the indices with different LAI value varied a lot. For LAI lower than 4 , indices showed good estimation s of LAI. DVI, SR, NDVI, RDVI, MSR, EVI, SAVI, OSAVI, MTVI2, and MDI (600-750 nm) exhibited good estimations of $R^{2}$ greater than 0.5 and RMSE value lower than 0.5 . This demonstrates the ability of these indices in retrieving low and moderate LAI value (LAI $<4)$. However, in case of LAI exceeding $4, \mathrm{R}^{2}$ and RMSE are not as good as that with LAI under 4 . Most indices are not able to estimate LAI with a fitted $R^{2}$ of higher than 0.5. Indices showed a decrease of $R^{2}$ from 0.1 to 0.2 . $\mathrm{R}^{2}$ of SR, NDVI, MSR, TVI, and corresponding LAI showed clear decrease, especially. The decrease of $R^{2}$ and the increase of RMSE reveal that these indices are not capable of inversing moderate- to-high LAI values.

It can be concluded from Table 4 that TTVI remains to be the best performed index among 15 indices with the highest $R^{2}$ and lowest RMSE (both for LAI value lower than 4 and greater than 4 ). Compared to other indices, TTVI has the best linear relationship with LAI and mitigates scattering effect. For LAI greater than 4, TTVI improved retrieval accuracy from 7.04 to $141.35 \%$ compared to EVI and SR respectively. Also, the retrieval accuracy increase of the new proposed index TTVI is obvious compared to original triangular vegetation index. This index is closer to the 1:1 line than the other indices and indicates the better linear relationship with LAI. The modified new index TTVI fulfilled the design criteria to be sensitive to LAI variation especially for high LAI value.

\section{Discussion}

Both hyperspectral and multispectral data were used for LAI estimation in this study. As can be seen from Figures 3 and 4, the performances of spectral indices were slightly different. According to the results derived from validation dataset, relationships between indices and LAI with ASD data behaved better than those with Sentinel-2 data. Possible reasons lie in the various spatial resolution and texture differences derived from the different observation heights between field sensors and spaceborne sensors. Field ASD data were collected at the observation height of $1.3 \mathrm{~m}$ above the ground which makes it more sensitive to plant structure information such as leaf angle and reflectance from stems at early growth stages. However, $786 \mathrm{~km}$ away from the earth, canopy pigment contents like 
chlorophyll content seem to have dominant influence for Sentinel-2 satellite data. Second, the closer distance between field ASD sensors and ground enables the pure pixel of reflectance from vegetation canopy, while satellite data may contain more information apart from winter wheat including ridges between adjacent rows and soil background. The two reasons mentioned above result in the different performances of indices for different sensors. The performances of TTVI from different sensors reveal that it is capable to be used both for hyperspectral and multispectral images. From the conclusions derived from 3.1 and 3.2, TTVI is suitable for LAI estimation on both hyperspectral and multispectral images which can make it widely used by numerous sensors. To be noted that TTVI was calculated by NIR and red-edge bands, it might not be possible to use for sensors without these bands, but it can be utilized by those with red-edge bands of similar wavelengths. The advent of spaceborne hyperspectral missions like Chinese GF-5 satellite and Italian PRISMA satellite brings opportunities for the development of these new indices and broadens the usage of these indices.

The second finding in this research indicates that saturation effect is a huge obstacle in LAI estimation. The major reasons leading to saturation effect may come from the contrast between NIR and red reflectance with the increase of LAI value. The ratio of NIR and red reflectance is nonlinear with LAI variation. NIR reflectance keeps increasing and red reflectance stops increasing when it is insensitive to chlorophyll content variation [54]. Instead of taking advantage of the contrast between the visible spectral reflectance, the proposed index utilized these wavelengths by calculating the area embraced by red-edge and NIR wavelengths. The area of triangle depends on the reflectance from red-edge and NIR bands. The area variation of TTVI mostly relies on the increase of NIR shoulder. Though 740 and $783 \mathrm{~nm}$ wavelengths are sensitive to chlorophyll content, they were much less affected than that for green and red bands [39]. Besides, the change of area caused by these two wavelengths can be overwhelmed by NIR reflectance. Red-edge point is sensitive to chlorophyll content, yet insensitive at high chlorophyll contents.

\section{Conclusions}

In this paper, 14 existing vegetation indices from five classes and a proposed index (transformed triangular vegetation index, TTVI) were tested to explore their potentials in LAI estimation. Field measured hyperspectral data and Sentinel-2 multispectral data were used for modeling and validation. According to the results, most indices exhibited nonlinear relationships with LAI and reached asymptotic with high vegetation cover when LAI value is greater than 4 . We replaced the three bands of TVI from green peak, minimum red absorption, and NIR shoulder to red-edge and NIR spectral bands $(740 \mathrm{~nm}, 783 \mathrm{~nm}, 865 \mathrm{~nm})$. The results demonstrated that TTVI is an appropriate candidate for winter wheat canopy LAI estimation. It exhibits the best linear relationship with LAI value both by hyperspectral and multispectral data. The experiments were conducted in two study sites (Shunyi, Beijing and Luohe, Henan) at four growth stages (tillering stage, stem elongation stage, heading stage, and milky stage of 2016 and 2019). TTVI was proved to be the best among the selected indices for LAI estimation with $\mathrm{R}^{2}$ of 0.60 and RMSE of 1.12 with field hyperspectral data. For Sentinel-2 data, it performed the best estimation with $\mathrm{R}^{2}$ of 0.59 and RMSE of 1.15 which improved the retrieval accuracy by $7.0 \%$ compared to EVI, $64.7 \%$ compared to MSR. This improvement might appear low but still performing in LAI estimation. TTVI can be capable of LAI estimation for both hyperspectral and multispectral sensors. Besides, according to analysis between indices and LAI with different value indicates that TTVI is capable for both low-to-moderate and moderate-to-high LAI estimation. The index is more sensitive to LAI variation and able to eliminate saturation effects for high vegetation cover.

Though the new index made improvement in eliminating saturation effect, more research needs to be done in the future. TTVI is able to improve LAI accuracy for winter wheat and more experiments can be conducted over different crops to validate the capability and robustness of the index. Also, classical vegetation indices like NDVI and EVI are still very good indices for low-to-moderate LAI estimation. TTVI showed better performance for both low-to-moderate and moderate-to-high LAI. The combination of two indices may bring new methods in LAI estimation. 
Author Contributions: N.X. performed the data analysis and wrote the manuscript. W.H. guided the research. Q.X. helped in designing the research, and reviewed and edited the manuscript. Y.S. helped with the statistical analysis. H.Y. conducted the field experiment in the first study site. Y.D., M.W., and G.S. provided suggestions for the study. Q.J. conducted the field experiment in the second study site. All authors have read and agreed to the published version of the manuscript.

Funding: This research was funded by National Key R\&D Program of China, grant number 2016YFB0501501; National special support program for high-level personnel recruitment (Wenjiang Huang); Ten-thousand Talents Program (Wenjiang Huang), National Natural Science Foundation of China, grant number 41871339; and the Science and Technology Service program of Chinese Academy of Sciences, grant number KFJ-STS-ZDTP-054.

Acknowledgments: The authors would like to thank Xianfeng Zhou, Huiqin Ma, Linyi Liu, Weiping Kong for collecting the field measurement data at Beijing Shunyi District. Also, the authors would like to thank Bin Wu, Qi Sun for conducting the field measurements at Luohe.

Conflicts of Interest: The authors declare no conflict of interest.

\section{References}

1. Chen, J.M.; Black, T.A. Defining leaf area index for non-flat leaves. Plant Cell Environ. 2010, 15, 421-429. [CrossRef]

2. Sharma, L.K.; Bali, S.K.; Dwyer, J.D.; Plant, A.B.; Bhowmik, A. A Case Study of Improving Yield Prediction and Sulfur Deficiency Detection Using Optical Sensors and Relationship of Historical Potato Yield with Weather Data in Maine. Sensors 2017, 17, 1095. [CrossRef] [PubMed]

3. Haboudane, D.; Miller, J.R.; Pattey, E.; Zarco-Tejada, P.J.; Strachan, I.B. Hyperspectral vegetation indices and novel algorithms for predicting green LAI of crop canopies: Modeling and validation in the context of precision agriculture. Remote Sens. Environ. 2004, 90, 337-352. [CrossRef]

4. Viña, A.; Gitelson, A.A.; Nguy-Robertson, A.L.; Peng, Y. Comparison of different vegetation indices for the remote assessment of green leaf area index of crops. Remote Sens. Environ. 2011, 115, 3468-3478. [CrossRef]

5. Sims, D.A.; Gamon, J.A. Relationships between leaf pigment content and spectral reflectance across a wide range of species, leaf structures and developmental stages. Remote Sens. Environ. 2002, 81, 337-354. [CrossRef]

6. Broge, N.H.; Leblanc, E. Comparing prediction power and stability of broadband and hyperspectral vegetation indices for estimation of green leaf area index and canopy chlorophyll density. Remote Sens. Environ. 2001, 76, 156-172. [CrossRef]

7. Myneni, R.B.; Ramakrishna, R.; Nemani, R.; Running, S.W. Estimation of global leaf area index and absorbed par using radiative transfer models. IEEE Trans. Geosci. Remote Sens. 2002, 35, 1380-1393. [CrossRef]

8. Darvishzadeh, R.; Atzberger, C.; Skidmore, A.; Schlerf, M. Mapping grassland leaf area index with airborne hyperspectral imagery: A comparison study of statistical approaches and inversion of radiative transfer models. ISPRS J. Photogramm. Remote Sens. 2011, 66, 894-906. [CrossRef]

9. Tol, C.; Verhoef, W.; Timmermans, J.; Verhoef, A.; Su, Z. An integrated model of soil-canopy spectral radiances, photosynthesis, fluorescence, temperature and energy balance. Biogeosci. Discuss. 2009, 6, 3109-3129.

10. Berger, K.; Atzberger, C.; Danner, M.; D’Urso, G.; Mauser, W.; Vuolo, F.; Hank, T. Evaluation of the PROSAIL Model Capabilities for Future Hyperspectral Model Environments: A Review Study. Remote Sens. 2018, 10, 26. [CrossRef]

11. Huete, A.R. A soil-adjusted vegetation index (SAVI). Remote Sens. Environ. 1988, 25, 295-309. [CrossRef]

12. Qi, J.; Chehbouni, A.; Huete, A.R.; Kerr, Y.H.; Sorooshian, S. A modified soil adjusted vegetation index. Remote Sens. Envrion. 1994, 48, 119-126. [CrossRef]

13. Baret, F.; Guyot, G. Potentials and limits of vegetation indices for LAI and APAR assessment. Remote Sens. Environ. 1991, 35, 161-173. [CrossRef]

14. Chen, J.M. Evaluation of Vegetation Indices and a Modified Simple Ratio for Boreal Applications. Can. J. Remote Sens. 1996, 22, 229-242. [CrossRef]

15. Colombo, R.; Bellingeri, D.; Fasolini, D.; Marino, C.M. Retrieval of leaf area index in different vegetation types using high resolution satellite data. Remote Sens. Environ. 2003, 86, 120-131. [CrossRef]

16. Fang, H.; Liang, S. Retrieving leaf area index with a neural network method: Simulation and validation. IEEE Trans. Geosci. Remote Sens. 2003, 41, 2052-2062. [CrossRef] 
17. Weiss, M.; Baret, F.; Leroy, M.; Hautecœur, O.; Bacour, C.; Prevol, L.; Bruguier, N. Validation of neural net techniques to estimate canopy biophysical variables from remote sensing data. Agronomie 2002, 22, 547-553. [CrossRef]

18. Upreti, D.H.W.; Kong, W.; Pascucci, S.; Pignatti, S.; Zhou, X.; Ye, H.; Casa, R. A Comparison of Hybrid Machine Learning Algorithms for the Retrieval of Wheat Biophysical Variables from Sentinel-2. Remote Sens. 2019, 11, 481. [CrossRef]

19. Zhu, Z.B.J.; Pan, Y.; Ganguly, S.; Anav, A.; Xu, L.; Samanta, A.; Piao, S.; Nemani, R.R.; Myneni, R.B. Global Data Sets of Vegetation Leaf Area Index (LAI)3g and Fraction of Photosynthetically Active Radiation (FPAR)3g Derived from Global Inventory Modeling and Mapping Studies (GIMMS) Normalized Difference Vegetation Index (NDVI3g) for the Period 1981 to 2011. Remote Sens. 2013, 5, 927-948. [CrossRef]

20. Xie, Q.; Dash, J.; Huang, W.; Peng, D.; Qin, Q.; Mortimer, H.; Dong, Y. Vegetation Indices Combining the Red and Red-Edge Spectral Information for Leaf Area Index Retrieval. IEEE J. Sel. Top. Appl. Earth Obs. Remote Sens. 2018, 11, 1482-1493. [CrossRef]

21. Xu, B.; Li, J.; Park, T.; Liu, Q.; Zeng, Y.; Yin, G.; Myneni, R.B. An integrated method for validating long-term leaf area index products using global networks of site-based measurements. Remote Sens. Environ. 2018, 209, 134-151. [CrossRef]

22. Xiao, Z.; Liang, S.; Wang, J.; Xiang, Y.; Zhao, X.; Song, J. Long-Time-Series Global Land Surface Satellite Leaf Area Index Product Derived from MODIS and AVHRR Surface Reflectance. IEEE Trans. Geosci. Remote Sens. 2016, 54, 5301-5318. [CrossRef]

23. Goel, N.S. Models of vegetation canopy reflectance and their use in estimation of biophysical parameters from reflectance data. Remote Sens. Rev. 1988, 4, 1-212. [CrossRef]

24. Swain, P.H.; Davis, S.M. Remote Sensing: The Quantitative Approach; McGraw-Hill Publishing Company, Inc.: New York, NY, USA, 1978.

25. Tucker, C.J. Red and photographic infrared linear combinations for monitoring vegetation. Remote Sens. Environ. 1979, 8, 127-150. [CrossRef]

26. Rouse, J.W. Monitoring vegetation systems in the great plains with ERTS. NASA Spec. Publ. 1974, $351,309$.

27. Jordan, C.F. Derivation of Leaf-Area Index from Quality of Light on the Forest Floor. Ecology 1969, 50, 663-666. [CrossRef]

28. Roujean, J.L.; Breon, F. Estimating PAR absorbed by vegetation from bidirectional reflectance measurements. Remote Sens. Environ. 1995, 51, 375-384. [CrossRef]

29. Jiang, Z.; Huete, A.R.; Didan, K.; Miura, T. Development of a two-band enhanced vegetation index without a blue band. Remote Sens. Environ. 2008, 112, 3833-3845. [CrossRef]

30. Rondeaux, G.; Steven, M.; Baret, F. Optimization of soil-adjusted vegetation indices. Remote Sens. Environ. 1996, 55, 95-107. [CrossRef]

31. Darvishzadeh, R.; Atzberger, C.; Skidmore, A.K.; Abkar, A.A. Leaf Area Index derivation from hyperspectral vegetation indicesand the red edge position. Int. J. Remote Sens. 2009, 30, 6199-6218. [CrossRef]

32. Salas, E.; Henebry, G. A new approach for the analysis of hyperspectral data: Theory and sensitivity analysis of the Moment Distance Method. Remote Sens. 2014, 6, 20-41. [CrossRef]

33. Zhao, J.; Liu, J.L.; Yang, L. A preliminary study on mechanism of LAI inversion saturation. ISPRS-International Archives of the Photogrammetry. Remote Sens. Spat. Inf. Sci. 2012, 39, 77-81.

34. Gitelson, A.A. Wide Dynamic Range Vegetation Index for remote quantification of biophysical characteristics of vegetation. J. Plant Physiol. 2004, 161, 165-173. [CrossRef] [PubMed]

35. Munden, R.; Curran, P.J.; Catt, J.A. The relationship between red edge and chlorophyll concentration in the Broadbalk winter wheat experiment at Rothamsted. Int. J. Remote Sens. 1994, 15, 705-709. [CrossRef]

36. Curran, P.J.; Windham, W.R.; Gholz, H.L. Exploring the relationship between reflectance red edge and chlorophyll concentration in slash pine leaves. Tree Physiol. 1995, 15, 33-48. [CrossRef]

37. Clevers, J.G.P.W.; De Jong, S.M.; Epema, G.F.; Van Der Meer, F.D.; Bakker, W.H.; Skidmore, A.K.; Scholte, K.H. Derivation of the red edge index using the MERIS standard band setting. Int. J. Remote Sens. 2002, 23, 3169-3184. [CrossRef]

38. Delegido, J.; Verrelst, J.; Alonso, L.; Moreno, J. Evaluation of Sentinel-2 red-edge bands for empirical estimation of green LAI and chlorophyll content. Sensors 2011, 11, 7063-7081. [CrossRef]

39. Dong, T.; Liu, J.; Shang, J.; Qian, B.; Ma, B.; Kovacs, J.M.; Shi, Y. Assessment of red-edge vegetation indices for crop leaf area index estimation. Remote Sens. Environ. 2019, 222, 133-143. [CrossRef] 
40. Boissard, P.; Pointel, J.G.; Huet, P. Reflectance, green leaf area index and ear hydric status of wheat from anthesis until maturity. Int. J. Remote Sens. 1993, 14, 2713-2729. [CrossRef]

41. Delegido, J.; Verrelst, J.; Meza, C.M.; Rivera, J.P.; Alonso, L.; Moreno, J. A red-edge spectral index for remote sensing estimation of green LAI over agroecosystems. Eur. J. Agron. 2013, 46, 42-52. [CrossRef]

42. White, J.D.; Running, S.W.; Nemani, R.; Keane, R.E.; Ryan, K.C. Measurement and remote sensing of LAI in Rocky Mountain montane ecosystems. Can. J. For. Res. 1997, 27, 1714-1727. [CrossRef]

43. Clevers, J.L.; Kooistra, L.; Van Den Brande, M. Using Sentinel-2 Data for Retrieving LAI and Leaf and Canopy Chlorophyll Content of a Potato Crop. Remote Sens. 2017, 9, 15. [CrossRef]

44. Revill, A.; Florence, A.; MacArthur, A.; Hoad, S.P.; Rees, R.M.; Williams, M. The Value of Sentinel-2 Spectral Bands for the Assessment of Winter Wheat Growth and Development. Remote Sens. 2019, 11, 2050. [CrossRef]

45. Berterretche, M.; Hudak, A.T.; Cohen, W.B.; Maiersperger, T.K.; Gower, S.T.; Dungan, J. Comparison of regression and geostatistical methods for mapping Leaf Area Index (LAI) with Landsat ETM+ data over a boreal forest. Remote Sens. Environ. 2005, 96, 49-61. [CrossRef]

46. Chen, J.M.; Cihlar, J. Retrieving leaf area index of boreal conifer forests using Landsat TM images. Remote Sens. Environ. 1996, 55, 153-162. [CrossRef]

47. Thomas, J.R.; Gausman, H.W. Leaf Reflectance vs. Leaf Chlorophyll and Carotenoid Concentrations for Eight Crops1. Agron. J. 1977, 69, 799-802. [CrossRef]

48. Kattenborn, T.; Schiefer, F.; Zarco-Tejada, P.; Schmidtlein, S. Advantages of retrieving pigment content mu $\mathrm{g} / \mathrm{cm}$ versus concentration \% from canopy reflectance. Remote Sens. Environ. 2019, 230, 111195. [CrossRef]

49. Van der Meer, F.D.; Clevers, J.G.P.W.; De Jong, S.M.; Bakker, W.H.; Epema, G.F.; Skidmore, A.K.; Scholte, K. Meriland: Meris Potential for Land Applications; BCRS: Wolverhampton, UK, 2000.

50. Clevers, J. The use of imaging spectrometry for agricultural applications. ISPRS J. Photogramm. Remote Sens. 1999, 54, 299-304. [CrossRef]

51. Kohavi, R. A Study of Cross-Validation and Bootstrap for Accuracy Estimation and Model Selection. Int. Jt. Conf. Artif. Intell. 1995, 14, 1137-1145.

52. Wang, Q.; Adiku, S.; Tenhunen, J.; Granier, A. On the relationship of NDVI with leaf area index in a deciduous forest site. Remote Sens. Environ. 2005, 94, 244-255. [CrossRef]

53. Xie, Q.; Huang, W.; Zhang, B.; Chen, P.; Song, X.; Pascucci, S.; Pignatti, S.; Laneve, G.; Dong, Y. Estimating Winter Wheat Leaf Area Index from Ground and Hyperspectral Observations Using Vegetation Indices. IEEE J. Sel. Top. Appl. Earth Obs. Remote Sens. 2016, 9, 771-780. [CrossRef]

54. Wu, C.; Niu, Z.; Tang, Q.; Huang, W. Estimating chlorophyll content from hyperspectral vegetation indices: Modeling and validation. Agric. For. Meteorol. 2008, 148, 1230-1241. [CrossRef] 